\title{
Evaluating The Impact of ERP Systems on Value Added: An applied study
}

\author{
Mohamed Aly Wahdan ${ }^{1}$ \\ Mahmoud Abd-Elwahab ${ }^{2}$ \\ Reham Mohamed Ahmed ${ }^{3}$
}

${ }^{1}$ Prof. Dr. Mohamed Aly Wahdan Professor of Auditing and Vice-Dean for Postgraduate Studies and Researches, Faculty of Commerce, Menoufia University, my research interests are Auditing ,AIS and tax Accounting.

Email:Wahdan@msm.nl

${ }^{2}$ Prof .Dr. Mahmoud Abd-Elwahab Emeritus Professor of Accounting Faculty of Commerce, Menoufia University. Research interests are financial Accounting, AIS and Auditing.

${ }^{3}$ Reham Mohamed Ahmed Holds a Master Degree in Commercial Science, Faculty of Commerce, Menoufia University, my research interests are AIS and Managerial Accounting.

Email:Merinda@yahoo.com 


\title{
Evaluating The Impact of ERP Systems on Value Added:
}

\section{An applied study}

\author{
Mohamed Aly Wahdan ${ }^{1}$
}

Mahmoud Abd-Elwahab ${ }^{2}$

\section{Reham Mohamed Ahmed ${ }^{3}$}

\begin{abstract}
The study aims to study and evaluate the relationship between the implementation of Enterprise Resources Planning (ERP) and value-added (VA) of firms. To achieve this aim, the literature related to the study had been reviewed, an applied study using data from financial statements and reports of El-Sewedy Electric Group of companies had been conducted. The findings of the study indicated that there is a statistically significant impact of the ERP systems on the annual interest, there is a statistically significant impact of the ERP systems on the annual profit, there is a statistically significant impact of the ERP systems on the annual taxes, there is a statistically significant impact of the ERP systems on the annual wages and salaries, there is a statistically significant correlation between ERP systems and VA of companies and there is a statistically significant impact of ERP systems on VA of companies.
\end{abstract}

Key words: Value added (VA), Enterprise Resources of Planning (ERP) system.

الملخص

يهدف البحث إلى دراسة وتقييم العلاقة بين تنفيذ تخطيط موارد المشروع (ERP) والقيمة المضافة للشركات. ولتحقيق هذا الهـف تم مراجعة الأدبيات الخاصة بالبحث، وتم عمل دراسة تطبيقية باستخدام بيانات من القوائم المالية والتقاريرالخاصة بمجموعة شركات السويدى اليكتريك. ولقد أشارت نتائج الدراسة إلى أن: هناك تأثير ذو دلالة إحصائية لأنظمة تخطيط موارد المشروع على مصروفات

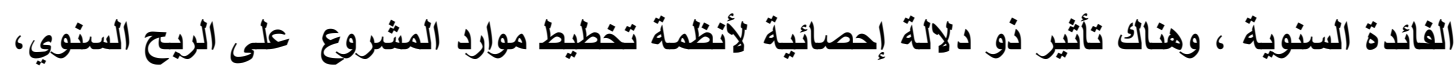

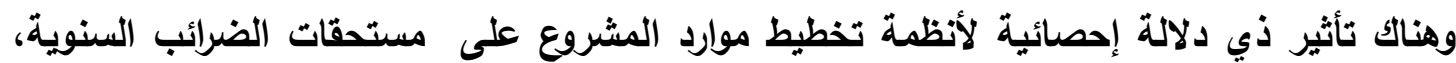
هناك تأثير ذو دلالة إحصائية لأنظمة تخطيط موارد المشروع على الأجور والرواتب السنوية، وهناك

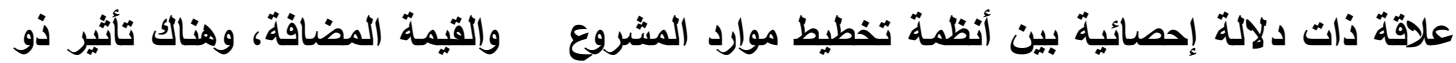
دلالة إحصائية لأنظمة تخطيط موارد المشروع على القيمة المضافة للشركات. 


\section{Introduction:}

Enter Resource Planning (ERP) systems (which can integrate data throughout the organization and support all major organizational functions) replace the complex and sometimes manual interfaces between different systems because the need to improve information acquisition from ERP systems and their transmission to information users.

ERP systems have many benefits for companies such as reducing competition and costs, increasing sales and profits, which has a positive effect on business owners in community companies through taxes. ERP is establishing linkages with suppliers, satisfying customers, and reducing waste.

Researchers use various approaches to study the impact of ERP systems with mixed results. So, some studies measured ERP with Accounting Information Systems (AIS) and other studies measure ERP with traditional accounting (Morris, 2011).

But there is no study evaluating the impact of ERP on value added (VA) of the company, so this study seeks to measure impact of ERP on VA .The study measures ERP with VA application on El Sewedy Electric Group companies in Egypt.

El Sewedy Electric Group companies apply ERP systems and compete for market share with global companies. Therefore, it seeks to increase value added (VA), and to achieve increasing sales, profits, stock prices and lower interest. Therefore, the main research questions examined in this paper are:

- To what extent does ERP implementation impact on the annual benefit of companies?

- To what extent does ERP implementation impact on the annual profit of companies?

- To what extent does the implementation of the ERP system impact on the annual taxes?

- To what extent does the implementation of the ERP system impact on the annual wages and salaries of companies' employees?

- Is there any relationship between the implementation of the ERP system and the VA? And what is the level of significance for this relationship?

- To what extent does the implementation of the ERP system impact on the companies' value added?

The outline of this paper is organized as follows: Section 2: deals with literature review and hypothesis development. Section 3: presents the impact of implementing ERP systems on companies. Section 4: provides the research methodology. Section 5: presents discussion and results. Section6: explains conclusion, limitations and points to future Research.

\section{Literature Review and Hypotheses Development}

In this section, the related literature is reviewed and the hypotheses are developed. Research will discuss previous studies related to the topic of research and divide them into two directions: First: Literature related to ERP \& Second: literature related to value added.

\section{First: Literature related to ERP}


The study of (Sedehi, 2015) aimed to explore the challenges and difficulties that (SMEs) small and medium-sized companies face in manufacturing when implementing best practices and information technology such as resource constraints and process complexity. The findings of the study indicated that configuration of ERP, adoption of ERP and users training of ERP systems have positive impact on achieving the organizational effectiveness in the case of a world renowned news agency. Furthermore, there is an importance for the IT managers in media industry to understand true picture of ERP effectiveness and the impact to which employees perceive it useful for their growth and motivation.

The study of (Hwang et al., 2011) aimed to define a model that shows the relative relationship between internal and external factors affecting the implementation of ERP systems and its (actual implementation, supplier capabilities, organizational capacity, supplier performance, organizational performance, and customer value). The findings of the study indicated that customer value is the final outcome of implementing ERP systems .In addition to identifying the main dimensions that must be taken into consideration during companies' implementation of ERP systems. Moreover, the relationship between the external environment and implementing ERP systems is not sufficiently clear.

The study of (Ali \& Younes, 2013) aimed to identify the benefits resulting from the implementation of ERP systems in industrial companies, in addition to the relationship between stakeholders and the benefits resulting from the implementation of ERP systems. The findings of the study indicated that the benefits achieved from implementing ERP systems are many benefits include: benefits for all stakeholders such as information for making the right decision and growth, benefits for employees and owners such as for learning. Moreover, implementing ERP systems has achieved the maximum benefit for companies and employees.

The study of (Elbardan\& Kholeif, 2017) aimed to determine the conviction that the changes in the IAF (Internal Auditing Function), as a response to ERP implementation, have not received the attention in academic research. The findings of the study indicated that attempts to establish new claims to knowledge provide valuable opportunities to study the processes through which claims are linked with attempts to expand and maintain the legitimacy of professional jurisdiction .Moreover, recognition to be given to ERP systems capabilities to facilitate the mobility of professional practice by legitimizing the new internal audit structure and practice in the new technological environment.

The study of (Shin et al., 2013) aimed to introduce the continuous auditing system based on continuous monitoring and its implementation methodology; in addition to present a systematic case study of actual continuous Auditing systems implemented in the financial industry and the manufacturing industry. The findings of the study indicated that the proposed method of implementing the continuous auditing system has the 2 stage approaches which can be applied to various kinds of companies in the 
ERP-based environment. In addition, the proposed cases have the important practical implications acquired in the process of implementing the continuous auditing system in the financial industry and the manufacturing industry.

The study of (Azaltun et al., 2013) aimed to determine the effect of the ERP systems on the cost of auditing period compared with traditional computerized (non-ERP) systems .furthermore, making a comparison between the price and cost of the audit period under the application of ERP systems and the price and cost of the audit period in light of the application of other computerized systems. The findings of the study indicated that for auditing firms under implementing ERP systems, prices are not reduced for clients.

The study of (Althonayan, 2013) aimed to evaluate the impact of ERP systems implementation on stakeholders' performance with an application to an academic organization. The findings of the study indicated that factors to consider stakeholders 'performance under ERP implementation include six significant factors in the system quality dimension (timeliness, flexibility, ease of use, content, currency and authorization) and two (reliability and responsiveness) in the service quality dimension. In addition to other factors that have a great influence on stakeholder performance: resistance to change, training and continuing education, allocate appropriate systems and support top management.

The study of (Al Rashid, 2013) aimed to create a comprehensive and holistic design of a model for implementing ERP in Saudi Arabia. It focuses on Managing roles and responsibilities among stakeholders in addition to study the factors that may prevent the success of the newly implemented ERP system. The findings of the study indicated that ERP can be an effective source of strategic decisions. Therefore, management support is important to the success of the application and confidence in the system by stakeholders. In addition to assessing the success of the system implementation is better after its implementation.

The study of (Tarhini et al., 2015) aimed to identify critical success factors for implementing ERP systems from a stakeholder perspective. The findings of the study indicated that the most important critical factors that contribute to the success of ERP systems are senior management managing change, interdepartmental communication and a better understanding. And these factors would help practitioners and managers to improve the chance of success in project implementation commitment, training, project management, vision and clear goals for an ERP system.

The study of (Tsai et al., 2014) aimed to determine the impact of information technology governance on providing value in the relationships between the quality of vendor service, the quality of consulting services, and the performance of providing an integrated technology suite performing ERP systems .The findings of the study indicated that providing value and quality of supplier/consultant service has a positive impact on improving ERP performance. 
The study of (Aljohani et al., 2015) aimed to identify the critical success factors in which the local ERP system has been replaced by systems, application and Products (SAP) ERP .The findings of the study indicated that success factors were trend pressure, reliance on foreign experts, poor integration and general negativity (most of the interviewed professionals stressed that the decision involved the personal desire of top management members. Moreover, such staff was influenced by Western universities and did not consider cultural and local needs .Also, SAP depends on foreign experts who experience difficulties in getting entry visas on occasion, in addition to their limited residency in the kingdom.

\section{Second: Literature related to value added}

The study of (Haller et al., 2018) aimed to determine the extent to which the information provided by the published value added can be used to achieve fair distribution among stakeholders .Moreover, to investigate value added information published in sustainability reports to determine if the information provided is useful for assessing distributional fairness among stakeholders. The findings of the study indicated that ethical and moral implications stress the societal issue of distributional fairness. It seems that companies are either reluctant to provide value added information that is useful, or deliberately use value added disclosures to obfuscate.

The study of (Jensen et al., 2014) aimed to summarize recent research findings and reflections on value added of facilities management and to outline perspectives for future research and development of the value added of financial management (FM). In addition to define a framework for future research on the value-added clause and developing the value added of financial management. The findings of the study indicated that the value added has a pivotal effect on the future development of financial management, methods of measuring performance, as well as new benefits for stakeholders. Furthermore, information reflecting distributional fairness is therefore compromised.

The study of (Olya et al., 2018) aimed to explore a value-added predictor in service industries based on the eight indicators of the prosperity index, namely economy, entrepreneurship, governance, education, health, safety and security, personal freedom and social capital. The findings of the study indicated that there are reasons or factors that lead to high and low degrees of value added for services and the greatest benefit from using the value added index in service industries is an indication of prosperity. Moreover the configurable conditions indicating a high/low level of value added in service industries can be used as a guiding strategy for marketers, investors and policy makers.

The study of (Aldama \&Zicari, 2012) aimed to present a group of experiments in Latin America. In addition to the model of preparing the value added statement, with an explanation of the importance of corporate social responsibility. The findings of the study indicated that the value added statement provides information on corporate 
social responsibility and a lot of financial information. Furthermore, economic information and the variety of experiences shown (different industries and diverse company ownership in separate countries) may suggest the wide potential of this reporting model.

The study of (Sharma \& Lenka, 2018) aimed to recommend the use of a financial metric, i.e. value-added statement, as a trigger to unlearning in organizations. The findings of the study indicated that the value added statement takes into account all stakeholders interests equally. Furthermore, value added disclosures in CSR reports seem to be more an obfuscation than useful corporate transparency of the economic and societal wealth (distribution) function of companies.

The study of (De Villiers et al., 2014) aimed to contribute to the current discussions about the concept of Integrated Reporting (IR) and provides a practical and useful proposal of an instrument that could help to apply the IR concept in corporate practice. The findings of the study indicated that value added statement" (VAS) has the potential to serve as a practical and effective reporting instrument for IR. Furthermore, reports on the monetary effects of different types of capital included in IR represent the concept of IR very well.

The study of (Hossain, 2017) aimed to identify the benefits of the value added statement as a supplement to the additional financial information needed by all stakeholders. In addition to its social and economic role is as means of accounting for communications in the global economy. The findings of the study indicated that value added statement solves many of the problems of pricing difficulties, as well as affects the enterprise's strategy by changing its goal from traditional profit to long-term value added. Moreover, the performance analysis of the company on the basis of value added figure reveals the distributive judgment in respect of all the participants of the company. This is not possible through the performance analysis on the basis of net profit figure only.

The study of (Rathi, 2017) aimed to address the need for change by presenting a relational view of the firm, based on the strategic value of the linkages with stakeholders. Furthermore, its implication appeared in terms of corporate performance evaluation and reporting systems. The relationship between the information has generated by the value added of stakeholders and evaluates the corporate performance of the company and reporting systems. The findings of the study indicated that benefits of the value added statement provides the financial and non-financial information that stakeholders need to make the right decision.

\section{Previous studies found that:}

- Success factors of ERP systems are the pressure of the trend, integration and dependence on foreign experts.

- Factors that must be taken into account in influencing stakeholder performance within the ERP implementation framework, including six significant factors in the system quality dimension (timeliness, flexibility, ease 
of use, content, currency and authorization) and two (reliability and responsiveness) in the service quality dimension.

o The benefits achieved from implementing ERP systems are many benefits for all stakeholders and include the benefits of information for making the right decision and the growth benefits for employees and owners.

- The proposed method for implementing a continuous Audit system has a twostage approach that can be applied to different types of companies in an ERP based environment.

- Benefits of the value added statement provides the financial and non-financial information that stakeholders need to make the right decision.

- Value-added information needs more understanding, comparability, and the effect of ethics on a society's issue of distributive justice.

Studies had reached the importance of value-added information, benefits of the value added statement, factors affecting the success of ERP systems and the impact of ERP systems on performance, stakeholders, and auditing process.

The current study aims to test the impact of an ERP system on value added: an applied study on El Sewedy Electric Group of companies. The previous studies did not deal with the impact of ERP system on annual (interest, taxes, wages and salaries and profit). So this is what the present study seeks through testing the hypotheses of the study to ascertain the extent of evaluating the impact of ERP systems on value added. Therefore the hypotheses can be developed as follows:

1. There is no statistically significant impact of ERP systems on the annual interest .

2. There is no statistically significant impact of ERP systems on the annual profit.

3. There is no statistically significant impact of ERP systems on the annual taxes.

4. There is no statistically significant impact of ERP systems on the value of annual wages and salaries.

5. There is no significant relationship between the ERP system and VA.

6. There is no statistically significant impact of ERP systems on VA of companies.

\section{The impact of implementing ERP systems on companies}

\section{3-1.The impact of implementing ERP systems on performance}

There are many studies related to the impact of ERP systems on performance, and studies differed on how to measure institutional performance and researchers' presentation of measurement from two aspects, a material (a tangible side). Some of these studies focus on financial performance, and others focus on operational performance and the third dimensions of the studies focus on financial and operational performance as the side physical, i.e. financial, matters to external parties, such as shareholders, and are concerned with reducing cost, manufacturing time, and increasing returns. The application of ERP systems was to improve the product, improve the relationship with suppliers, and reduce waste of expenses and time, by having a unified database that contained all information. The non-physical side ERP systems have an important role in controlling inventory by providing accurate and 
timely information that contributes to making the right decision that enhances the competitiveness of the company and increases savings and profits (Shen et al., 2016).

\section{3-2. The impact of implementing ERP systems on accounting}

The managerial accountant focuses on analyzing information used by ERP systems and with the presence of a complex administration that supports that the ERP system has a positive impact on management accounting systems, as the systems reduce the time for data collection and processing, which allows a lot of time to participate in activities that add value to the organization and decision-making process. So, it contributes to the emergence of new roles for the managerial accountant such as participation in management and the development of ERP systems (Wahdan, 2012).

\section{3-3. The impact of implementing ERP systems on internal audit}

Some studies have presents the effect of ERP systems on internal audit, and results of many studies have indicated a decrease in financial and operational risks and an increase in technical risks, and this increase in risks is mitigated to some extent through ability of these systems to evaluate and manage these risks. Other studies have presented the impact of internal audit on ERP systems and their results indicated that the internal audit meets ERP skills by providing internal training for employees (Azaltun, 2013).

\section{3-4.The impact of implementing ERP systems on corporate governance}

The improvement in the performance of the company's operations resulted from an increase in corporate governance that applies ERP systems, as in studies (Al-Jinbaz, 2018; Elnasar, 2013; Ghader, 2012). These studies indicated that ERP system will play a role in activating corporate governance by meeting one of the pillars of governance, which is disclosure (providing financial information in the form of reports that meet all the needs of financial reporting users (Al-Jinbaz, 2018).

\section{3-5. The impact of implementing ERP systems on external audit}

It can be said that the summary of audit challenges is limited to the level of understanding of the ERP system (process audits, interface between internal audit and external audit, electronic information, data issues, computer interfaces and managing expectations) (Kanellou \& Spathis, 2009).

\section{Research methodology:}

Methodology of an applied study includes society and sample, data collection methods, study variables and statistical techniques.

\section{4-1 Society and Sample}

Society: the study will concentrate on organizations applying ERP in Egypt,

(The study will concentrate on companies listed in Egyptian Stock Exchange). 
Sample: this study will be applied on the manufacturing companies exactly El Sewedy Electric Group companies.

\section{4-2 Data collection method:}

In order to achieve the objectives of the study, the authors relied on the following sources:

Primary data can be obtained from El-Sewedy Electric Group companies (which apply ERP) and they can provide data for the last ten or twelve years as well as the financial statements for the same period and finance and accounting departments.

Secondary data such as statistics (the study search in 2 time chain: 2007:2010, 2011:2014) and archived data can be obtained from the websites.

\section{4-3.The study variables:}

- Independent variable $(\mathrm{X})$ is ERP system including variables .It is clamped (0 $-1)$.

- Dependent variable (Y) is VA including variables from Y1 to Y4 .So VA(Y) $=\mathrm{y} 1+\mathrm{y} 2+\mathrm{y} 3+\mathrm{y} 4 . \mathrm{VA}=$ annual interest + annual taxes + annual wages and salaries+ annual profit.

- Control variable: size of company \& the change in exchange rates \& the change in share prices.

\section{4-4. Statistical techniques}

The researchers supposed to use the following statistical techniques to test the hypotheses:

- Descriptive statistics

- Using the linear regression technique to recognize the impact of ERP on annual profit, annual interest, annual taxes, annual salaries and wages and VA.

- T test to test the difference between two independent paired samples.

- Using the correlation technique to test the relationship between the ERP and the value added.

\section{Discussion and Results}

The researchers used one of the measures of the central tendency, which is the arithmetic mean to find out the values around which the values of research variables are concentrated. Despite the importance and usefulness of the arithmetic mean, it does not fully explain the nature of the distribution. Then the researchers used the standard deviation as one of the most important scattering scales to find out the degree of spread of the values of the research variables around the arithmetic mean.

Table (1) shows the descriptive data of the El Sewedy Electric Group of companies before and after applying ERP systems in El Sewedy Electric Group of companies. 
Table (1): Descriptive data before and after application of ERP systems

\begin{tabular}{|l|l|l|l|}
\hline Symbol & Variable & Statistical mean & Sigma \\
\hline Y1_Be & Annual profit & 6996665433.75 & 104425455.26 \\
\hline Y2_Be & Annual taxes & 34219856.50 & 34768194.95 \\
\hline Y3_Be & Annual wages and salaries & 486694777.75 & 237017959.56 \\
\hline Y4_Be & Annual financing cost & 189112728.25 & 59454407.06 \\
\hline Y_Be & Value Added & 1409695496.25 & 316769599.65 \\
\hline Y1_Af & Annual profit & 315531039.50 & 205883536.82 \\
\hline Y2_Af & Annual taxes & 123844194.50 & 51072326.25 \\
\hline Y3_Af & Annual wages and salaries & 920222207.25 & 286782359.90 \\
\hline Y4_Af & Annual financing cost & 441873528.50 & 79670389.65 \\
\hline Y_Af & Value Added & 1801084155.50 & $308,458,62.41$ \\
\hline
\end{tabular}

Annual profit:

1. The arithmetic mean of the annual profit of EL Sewedy Electric Group of companies after the application of ERP systems was lower than before the application, where the average annual profit of the company after application was (315531039.50) while before application was equal to (699665433.75).

2. While the standard deviation of the annual profit of the El- Sewedy Electric Group of companies after the application of ERP systems was greater than before the application, where the standard deviation of the annual profit of the companies after application was (205883536.82) while before implementing it was equal to (104425455.26).

\section{For annual taxes:}

1. The arithmetic mean of the annual taxes of El Sewedy Electric Group of companies after the application of ERP systems is greater than before the application, where the average arithmetic of the annual taxes of the companies after application (123844194.50) while before application was equal to (34219856.50).

2. While the standard deviation of the annual taxes of El- Sewedy Electric Group of companies after applying the ERP systems was greater than before the application, where the standard deviation of the annual taxes of the companies after application was (51072326.25) while before implementation it was equal to (34768194.95).

\section{Annual wages and salaries:}

1. The arithmetic average of the annual wages and salaries of the El Sewedy Electric Group of companies after the application of ERP systems is greater 
than before the application, where the average arithmetic of the companies' annual wages and salaries after application reached (920222207.25) while before application was equal to (486697477.75).

2. Also, the standard deviation of the annual wages and salaries of the El Sewedy Electric Group of companies after the application of ERP systems is greater than before the application, where the standard deviation of annual wages and salaries of the companies after application reached (286782359.90) while before the application was equal to (237017959.56).

\section{Annual financing cost (Interest):}

1. The arithmetic average of the annual financing cost of the El Sewedy Electric Group of companies after applying ERP systems is greater than before the application, where the average mean of the annual financing cost of the companies after application was (441873528.50) while before application was equal to (189112728.25).

2. Just as the standard deviation of the annual cost of financing for the El Sewedy Electric Group of companies after the application of ERP systems was greater than before the application, as the standard deviation of the annual cost of funding for the companies after application reached (79670389.65) while before application was equal to (59454407.06).

\section{For the annual value added:}

1. The arithmetic mean of the annual value added of the El Sewedy Electric Group of companies after the application of the ERP is greater than before the application, where the average arithmetic of the annual value added of the companies after application (1801084155.50) while before application was equal to $(1409695496.25)$

2. On the contrary, the searcher found that the standard deviation of the annual value added of the El Sewedy Electric Group of companies after the application of ERP systems is less than before the application, as the standard deviation of the annual value added of the companies after application reached (30845862.41) while before application was equal to (316769599.65).

This reflects the increase in the average annual value added and the decrease in the standard deviation of the El Sewedy Electric Group of companies that the application of ERP systems gives an indication that it has a tangible impact on VA of the companies and there is relationship between the ERP system and VA.

The second part of the analysis, which is the advanced statistical analysis of the test of the validity of the study hypotheses, and it includes three tests as follow: 
- $\quad$ Statistical analysis using the T test for the difference between two independent paired samples Test (double samples) with a confidence degree of $95 \%$, to test the validity of the hypotheses.

The researchers will test the extent of the impact of the application of ERP systems on the level of the companies as a whole. Table (2) shows the results of the T (Paired Samples Test) test at the companies' level.

Table (2) company-wide T (Paired Samples Test) results

\begin{tabular}{|c|l|l|l|}
\hline Variables & $\begin{array}{l}\text { Degrees of } \\
\text { freedom }\end{array}$ & T value & Sigma (moral) \\
\hline Y1_Be - Y1_Af & 3 & 6.539 & 0.008 \\
\hline Y2_Be - Y2_Af & 3 & $(7.800)$ & 0.004 \\
\hline Y3_Be - Y3_Af & 3 & $(6.191)$ & 0.008 \\
\hline Y4_Be - Y4_Af & 3 & $(3.759)$ & 0.033 \\
\hline Y_Be - Y_Af & 3 & $(4.973)$ & 0.016 \\
\hline
\end{tabular}

Through the results of the T test (Paired Samples Test) on the companies' level, the researchers found that the application of the ERP systems had a significant impact on all variables as follows: (value added) where the level of significance was (0.016), and the variables (annual profit, annual taxes, annual wages and salaries and the annual financing cost of the company) where the level of significance, respectively, was as follows $(0.008,0.004,0.008,0.033)$ which are all less than (0.05). Consequently, the researchers found that there is a significant impact of ERP systems on all variables (value added, annual profit, annual taxes, annual wages and salaries, and the annual financing cost of the companies) at the companies' level.

Therefore, the null hypotheses from one to four are rejected and the alternative hypotheses from one to four are accepted the following assumptions that:

- There is a statistically significant impact of the ERP systems on the annual profit value.

- There is a statistically significant impact of the ERP systems on the value of annual wages and salaries.

- There is a statistically significant impact of the ERP systems on the annual taxes.

- There is a statistically significant impact of the ERP systems on the annual interest value.

\section{Correlation analysis to test the validity of the fifth hypothesis}

"There is no significant relationship between the ERP system and VA".

One way to find and evaluate the relationship between two or more variables is to calculate the correlation coefficient. This parameter shows the type and degree of 
relationship between the study variables. Therefore, if the correlation coefficient signal is positive, then this indicates the existence of a direct correlation, and if the correlation coefficient signal is negative, then this indicates the existence of an inverse relationship or negative correlation between the variables. If the value of the correlation coefficient is zero, this indicates that there is no relationship between the variables, that is, the correlation between them is zero. Moreover, the correlation coefficient ranges between $(+1,-1)$. Whenever the correlation coefficient value approaches the correct one, it indicated that the correlation between the variables is strong, but if the correlation coefficient value approaches zero, it indicated that the correlation between the variables is weak. If correlation coefficient takes the value $(+1)$, this correlation coefficient indicates a positive correlation between the variables. If the correlation coefficient takes the value $(-1)$, this indicates that there is a complete negative correlation between the variables.

The researchers will display the Parson Correlation matrix to display the correlation coefficient of Parson between the dependent variable (VA for the companies) and the independent variable (ERP systems) at the companies' level as in table (3) that shows the correlation between study variables.

Table (3) The matrix displays the correlation between study variables

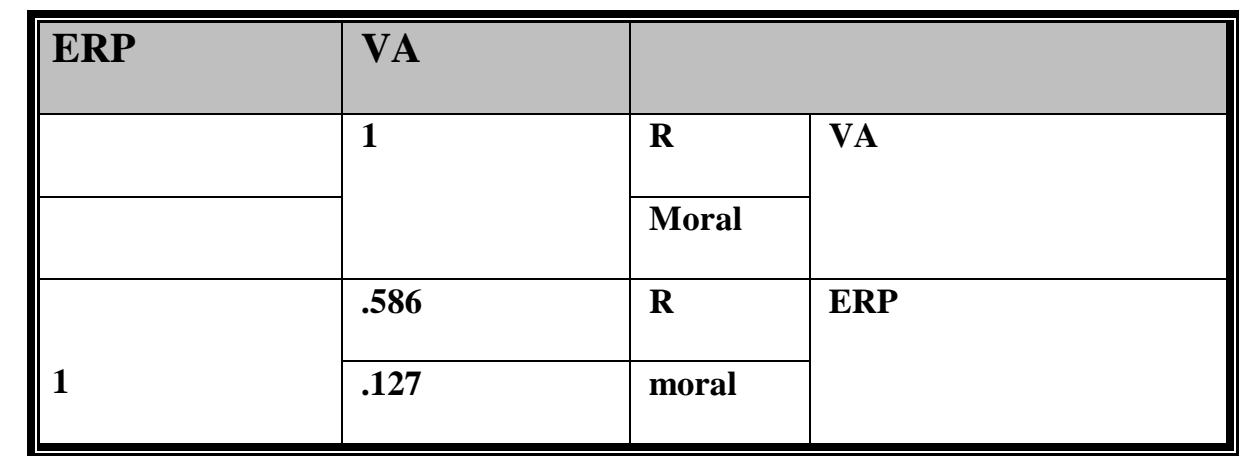

It is clear from Table (3) that:

An intermediate and non-significant direct correlation relationship between the dependent variable Y (the company's annual added value) and the independent variable (ERP systems) where the correlation coefficient reached (0.586) at a significant level (0.127).

It is clear from the previous presentation that there is an intermediate direct correlation between the independent variable (ERP systems) and the dependent variable (value added of the company VA), even if it is not significant.

The correlation matrix can be displayed between the independent variable ERP and each component of the value added (annual financing cost, annual taxes, annual wages and salaries and annual profit), as in Table No. (4) As follows: 
Table (4): the correlation matrix between the VA components and the independent variable ERP.

\begin{tabular}{|c|c|c|}
\hline$\overline{E \text { ERP }}$ & & \multirow{3}{*}{ Y1 } \\
\hline$-0.805 *$ & $\mathbf{R}$ & \\
\hline 0.016 & Moral & \\
\hline $0.764 *$ & $\mathbf{R}$ & \multirow[b]{2}{*}{ Y2 } \\
\hline 0.027 & Moral & \\
\hline 0.689 & $\mathbf{R}$ & \multirow[t]{2}{*}{ Y3 } \\
\hline 0.059 & Moral & \\
\hline $0.901 * *$ & $\mathbf{R}$ & \multirow[t]{2}{*}{ Y4 } \\
\hline 0.002 & Moral & \\
\hline
\end{tabular}

It is clear from Table (4) that there are:

1) A strong and significant inverse correlation relationship between the first component of the dependent variable $\mathrm{Y}$ (annual profit $\mathrm{Y} 1$ ) and the independent variable (ERP) where the correlation coefficient was (- 0.805) and at a significant level (0.016).

2) A strong and significant direct correlation relationship between the two variables (Y4, Y2), the second and fourth components of the dependent variable (annual financing cost Y4, annual taxes Y2) and independent variable (ERP), where the correlation coefficient on the soil was as follows $(0.901,0.764)$. The level of significance, respectively, is as follows $(0.002$, $0.027)$.

3) An intermediate and non-significant direct correlation relationship between the third component of the dependent variable Y (annual wages and salaries Y3) and the independent variable (ERP), where the correlation coefficient was (0.689) and at a significant level (0.059).

4) Through the previous offer, researchers found that it is possible to reject the fifth null hypothesis and accept the fifth alternative hypothesis that "there is a statistically significant correlation between ERP systems and VA of the companies".

(4/3): Test the study hypotheses and analyze the results 
Simple Linear Regression is used to be included with the statistical analysis of the sixth hypothesis. The objective of the linear regression analysis is to predict the value of the dependent variable using the independent variable and to obtain a mathematical equation that expresses the relationship between the dependent variable and the independent variable, as well as knowing the ratio of the influence of the independent variable on the changes in the dependent variable. We will address the results of the analysis as follows:

Table (5) illustrates the linear regression analysis that shows the values of each of the combined simple coefficient of $\mathrm{R}$ for the independent variable impacting the dependent variable, $\mathrm{R} 2$ of the variable and the correction factor of R-2 through which determined the ratio which the independent variable was able to explain the changes to the dependent variable.

It is clear from this table that the values of the simple correlation coefficient reached (0.586) while the coefficient of determination was R2 (0.343) while the corrected coefficient of determination was R-2 (0.234), which means that independent variable was able to explain $23.4 \%$ of the changes taking place on the variable the follower and the rest are $76.6 \%$ due to other factors such as: size of the company, the change in exchange rates and the change in share prices. As shown in Table (4), the reason for the low rate of influence is due to the causes of political instability that affected the economy.

Table (5) the correlation coefficient and the coefficient of the independent variables affecting the dependent variable

\begin{tabular}{|l|l|l|l|}
\hline Variable & $\begin{array}{l}\text { Correlation } \\
\text { coefficient } \mathbf{R}\end{array}$ & $\begin{array}{l}\mathbf{R 2} \text { coefficient of } \\
\text { determination }\end{array}$ & $\begin{array}{l}\text { Corrected } \\
\text { determination } \\
\text { coefficient R-2 }\end{array}$ \\
\hline ERP & $\mathbf{0 . 5 8 6}$ & $\mathbf{0 . 3 4 3}$ & $\mathbf{0 . 2 3 4}$ \\
\hline
\end{tabular}

At the level of significance $(0.05)$

From the table (6) the values of the analysis of variance through which it is possible to know the explanatory power of the model as a whole through a statistic F. From the table of analysis of variance, the significance of the test is $\mathrm{F}(0.05<\mathrm{P})$, where the value of $\mathrm{P}$-value or significance $(0.127)$ and the statistical value of $\mathrm{F}$ (3.134), which confirms the low explanatory strength of the model statistically. As shown in Table No. (6).

Table (6) Calculated value and level of significance

\begin{tabular}{|l|l|l|}
\hline Variable & Computed F & Moral \\
\hline ERP & $\mathbf{3 . 1 3 4}$ & $\mathbf{0 . 1 2 7}$ \\
\hline
\end{tabular}

Table (7) displays the value of the constant, the regression coefficient, and its statistical significance for the independent variable impacting the dependent variable. 
Table (7) Calculated value of the constant

\begin{tabular}{|l|l|l|l|}
\hline Variable & Parameter value & T test value & Moral \\
\hline $\begin{array}{l}\text { Non-standard } \\
\text { constant term B }\end{array}$ & 1409695496.3 & 9.018 & 0.000 \\
\hline ERP & $\mathbf{3 9 1 3 8 8 6 5 9 . 2 5}$ & $\mathbf{1 . 7 7 0}$ & $\mathbf{0 . 1 2 7}$ \\
\hline
\end{tabular}

At the level of significance (0.05)

From the Table (7) it is clear that the independent variable was not significant in the regression model according to the $\mathrm{T}$ test, where the significance (0.127) and the statistic value $\mathrm{T}(1.77)$ were significant. The stage regression equation can also be found using non-standard Beta (fixed term) as follows:

(Corporate Value Added) $\mathrm{Y}=1409695496.3+391388659.25$ (ERP Systems).

So, the sixth null hypothesis can be rejected and accept the alternative hypothesis (There is an impact of ERP system on value added of the companies.

\section{Conclusion, Limitations and Future Research}

\section{6-1. Conclusion:}

There is an Impact of ERP systems on annual wages and salaries. Therefore, increasing wages and salaries has a negative effect on the company's added value but it has a good effect on employees.

There is an Impact of ERP systems on annual profit: The implementation of ERP increases profit. Also, increases the financial capacity of people such as low-income people, through the distribution of profits that leads to the stability and growth of the company and its ability to compete, which increases the added value of the company.

There is an Impact of ERP systems on annual taxes: The implementation of ERP leads to an increase in the annual taxes in which companies contribute their share of taxes to the general budget, which in turn provides services to citizens and companies, thus supporting society, which in turn increases customer loyalty to the company and increases the added value of the company.

There is an Impact of ERP system on annual interest: Companies have been waiting for lower interest rates than embers, which will help them in the coming period to implement expansions or new projects that they wish to implement. The rate cut encourages investors to come back again to borrow strongly to implement more expansions and new projects, as well as reduce financing costs and the increase in revenues and profit, which increases the added value of the company.

There is a positive relationship between ERP systems and VA of the companies, as well as there is an impact of ERP systems on VA of the companies.

\section{6-2. Contribution and Implications}

The paper makes a number of timely contributions to the existing literature and has political implications for various future companies in the world. First, it complements the literature and broadens its scope to include the impact of ERP systems on corporate value added. Second, it is the first study to present a case study on the impact of ERP systems on the value added of companies in the world. Third, the 
application of value-added ERP systems is a new trend. It becomes a prerequisite after accelerating new technologies because of their benefits to stakeholders, so companies need a very high quality to move forward as most developed countries and few developing countries are already preparing the value-added statement and applying ERP systems to reach the desire for success and growth, and the ability to compete. Finally, the ERP systems will be reflected in more disclosure and transparency of the added value, including contributing to the investment on the company's infrastructure to keep pace with the new management systems that will definitely reflect on the company's performance in terms of efficiency and effectiveness.

\section{6-3. Limitations and future studies}

There are some limitations for the study as follows: (1) The study concentrates on manufacturing companies applying ERP in Egypt, exactly El- Sewedy Electric Group companies. (2) The study concentrates on companies listed in Egyptian Stock Exchange (financial data through time series: 2007:2010, 2011:2014. (3) The study concentrates on comprehensive ERP system contains (Financial ERP system, support ERP systems and an operational ERP system).

The researchers suggests a study for the impact of ERP systems in integration with Accounting for Resource Consumption (RCA) on VA in the service sector, the commercial sector, and the industrial sector, the impact of ERP on the environmental side in Egypt, the impact of IT on VA, and the impact of XPRL on VA.

\section{References}

Aldama, L. P., \& Zicari, A. (2012). Value-added reporting as a tool for sustainability: a Latin American experience. Corporate Governance: International Journal of Business in Society, 12(4), 485-498.

Ali, B. M., \& Younes, B. (2013). The impact of information systems on user performance: an exploratory study. Journal of Knowledge Management, Economics and Information Technology, 3(2), 128-154

Al-Jinbaz, A.M.M. (2018). The effect of implementing Enterprise Resource Planning on the efficiency of accounting data (Doctoral dissertation, college of Economics, Kai University).

Aljohani, A. M., Peng, A., \& Nunes, M. (2015). Critical factors leading to ERP replacement in Higher Education Institutions in Saudi Arabia: preliminary results. IConference 2015 Proceedings, 1-5.

Al Rashid, W. (2013). Managing stakeholders in enterprise resource planning (ERP) contexta proposed model of effective implementation (Doctoral dissertation, University of Salford).

Althonayan, M. (2013). Evaluating stakeholders performance of ERP systems in Saudi Arabia higher education (Doctoral dissertation, Brunel University, School of Information Systems, Computing and Mathematics).

Azaltun, M., Batibay, İ., Calayoglu, I., Mert, H., \& Tastan, H. (2013). The Impact of Enterprise Resource Planning (ERP) System on the Cost and Price of Auditing: Auditor's Perspective. Journal of Modern Accounting and Auditing, 9(4), 497-504.

De Villiers, C., Unerman, J., Rinaldi, L., Haller, A., \& van Staden, C. (2014). The value added statement-an appropriate instrument for Integrated Reporting. Accounting, Auditing \& Accountability Journal, 27(7), 1190-1216. 
Elbardan, H., \& Kholeif, A. O. R. (2017). ERP, internal auditing and corporate governance. In Enterprise Resource Planning, Corporate Governance and Internal Auditing (pp. 13-54). Palgrave Macmillan, Cham.

Haller, A., Van Staden, C. J., \& Landis, C. (2018). Value added as part of sustainability reporting: reporting on distributional fairness or obfuscation?. Journal of business ethics, 152(3), 763-781.

Hossain, M. A. (2017). Value added statement: A part of social responsibility reporting. Journal of Finance and Accounting, 5(2), 74-79.

Hwang, W. (2011). The drivers of ERP implementation and its impact on organizational capabilities and performance and customer value (Doctoral dissertation, University of Toledo).

Jensen, P. A., van der Voordt, T., Coenen, C., \& Sarasoja, A. L. (2014). Reflecting on future research concerning the added value of FM. Facilities, 32(13/14), 856-870.

Kanellou, A., \& Spathis, C. (2009). ERP systems and auditing: a review. In 6th International Conference on Enterprise Systems, Accounting and Logistics, Thessaloniki, Greece.

Morris, J. J. (2011). The impact of enterprise resource planning (ERP) systems on the effectiveness of internal controls over financial reporting. Journal of information systems, 25(1), 129-157.

Olya, H., Altinay, L., \& De Vita, G. (2018). An Exploratory Study of Value Added Services. Journal of Services Marketing, 32(3), 334-345.

Rathi, R. (2017). Value Added Statement: A New Dimension to Accounting Communication. International Journal of Applied Research, 3 (7), 1193-1197.

Sedehi, A. (2015). Evaluating the impacts of enterprise resource planning on organizational performance for small to medium enterprises in manufacturing (Doctoral dissertation, Georgia Institute of Technology).

Sharma, S., \& Lenka, U. (2019). Value-added statement as a trigger to organizational unlearning. Development and Learning in Organizations: An International Journal, 33 (6), 2225 .

Shen, Y. C., Chen, P. S., \& Wang, C. H. (2016). A study of enterprise resource planning (ERP) system performance measurement using the quantitative balanced scorecard approach. Computers in Industry, 75, 127-139.

Shin, I. H., Lee, M. G., \& Park, W. (2013). Implementation of the continuous auditing system in the ERP-based environment. Managerial Auditing Journal, 28(7), 592-627.

Tarhini, A., Ammar, H., Tarhini, T., \& Masa'deh, R. E. (2015). Analysis of the critical success factors for enterprise resource planning implementation from stakeholders' perspective: A systematic review. International Business Research, 8(4), 25-40.

Tsai, W. H., Chou, Y. W., Leu, J. D., Chen, D. C., \& Tsaur, T. S. (2015). Investigation of the mediating effects of IT governance-value delivery on service quality and ERP performance. Enterprise Information Systems, 9(2), 139-160.

Wahdan A.M. (2012). Evaluation of the impact of ERP systems on management accounting and management accountant in Egyptian business enterprises: a field study. El Tamweel and El Tegarah Journal, 1(4), 275-330. 